\title{
Review Article \\ The Utility of Geometric Morphometrics to Elucidate Pathways of Cichlid Fish Evolution
}

\author{
Michaela Kerschbaumer and Christian Sturmbauer \\ Department of Zoology, Karl-Franzens University of Graz, Universitätsplatz 2, 8010 Graz, Austria \\ Correspondence should be addressed to Michaela Kerschbaumer, michaela.kerschbaumer@uni-graz.at
}

Received 22 December 2010; Accepted 29 March 2011

Academic Editor: Tetsumi Takahashi

Copyright ( $) 2011$ M. Kerschbaumer and C. Sturmbauer. This is an open access article distributed under the Creative Commons Attribution License, which permits unrestricted use, distribution, and reproduction in any medium, provided the original work is properly cited.

\begin{abstract}
Fishes of the family Cichlidae are famous for their spectacular species flocks and therefore constitute a model system for the study of the pathways of adaptive radiation. Their radiation is connected to trophic specialization, manifested in dentition, head morphology, and body shape. Geometric morphometric methods have been established as efficient tools to quantify such differences in overall body shape or in particular morphological structures and meanwhile found wide application in evolutionary biology. As a common feature, these approaches define and analyze coordinates of anatomical landmarks, rather than traditional counts or measurements. Geometric morphometric methods have several merits compared to traditional morphometrics, particularly for the distinction and analysis of closely related entities. Cichlid evolutionary research benefits from the efficiency of data acquisition, the manifold opportunities of analyses, and the potential to visualize shape changes of those landmark-based methods. This paper briefly introduces to the concepts and methods of geometric morphometrics and presents a selection of publications where those techniques have been successfully applied to various aspects of cichlid fish diversification.
\end{abstract}

\section{Introduction}

Cichlid fishes are the most species-rich family of all teleost fishes, and their diversity is centered in the Great East African Lakes where more than 2000 species [1] evolved within the past five to six million years [2]. Consequently, the species assemblages of the three Great East African Lakes Victoria, Malawi, and Tanganyika represent the fastest vertebrate radiations known. Along with splitting into numerous species cichlid fishes have diversified into all imaginable ecological niches, manifested in spectacular diversification of the trophic apparatus. Cichlid fishes thus stand out as a paradigm for explosive speciation and adaptive radiation; their multitude of body shapes, specializations, colors, and behaviors is unsurpassed [3-10]. Their impressive ecomor-phological diversity is highlighted by the number of two-hundred-and-twenty recognized genera. The family Cichlidae has a wide distribution, spanning the southern tip of India and Sri Lanka with three species, Madagascar with 47 taxa in five genera (http://www.cichlid-forum.com/articles/ species_list_madagascar.php), Central and South America with 400-500 species, and Africa with probably over 2500 species. Interestingly, cichlids have not colonized Australia. In accord with the sequence of the split of Gondwana, Indian and Malagasy cichlids form the most ancestral split in the diversification of cichlid fishes, followed by the split between the African and American lineages [11-15]. Only few species colonized North America and Asia (Jordan valley and Iran). The evolutionary age of cichlids is thus constrained by vicariance to 130-165 million years and the split between African and American cichlids to about 70-90 million years [16].

While riverine ecosystems tend to be relatively speciespoor [17-19] — with the exception of the large South American rivers and perhaps the Zambezi system [20] lakes comprise extremely species-rich communities. Their hotspot of biodiversity clearly lies in the three Great East African Lakes, Victoria, Malawi, and Tanganyika, where an 
estimate of $1800-2000$ species, that is, $60 \%$ of the total cichlid diversity, are centered in species flocks [7]. Intralacustrine speciation has thus been put forward as the most common mode of diversification. Seehausen [21] listed 27 lacustrine radiations of cichlid fishes in Africa alone. As in all these lakes cichlid fish invariably form the most species-rich teleost lineage, they consistently outcompeted other fish groups when colonizing newly emerging lacustrine ecosystems [3].

Adaptive radiation has been defined as the process of extremely rapid species formation coupled with ecological, morphological, and behavioral diversification [22]. The onset of adaptive radiation often requires two conditions to be met $[23,24]$ : (1) the formation of a new habitat or a dramatic change of an already existing habitat and (2) the possession of a key innovation, that is, a set of traits allowing for rapid adaptation towards novel niches. Thereby, one feature or a certain set of features allows one particular group to outrun the other taxa in the speciation and diversification process. In the case of East African lakes, several teleost groups had the same chance to colonize the newly emerged lakes: cyprinids, characins, mormyrids, various catfish, sardines, Nile perches, and spiny eels; but judging from endemicity rates, only cichlids underwent major diversification. In the case of cichlid fishes the key innovation may be a highly effective combination of factors: two sets of jaws (the oral jaws and the pharyngeal jaws; [25]) and a highly effective brood care system. The oral jaws deal with food acquisition and manipulation, and the pharyngeal jaws process food in a wide variety of ways before swallowing. Both jaws have evolved to realize diverse foraging strategies. Concerning brood care, cichlids invariably care for eggs and their young [4]. Ancestral lineages are substrate breeders from which several groups branched off by independently evolving various modes of mouthbrooding, that is, incubating the eggs and/or fry in the buccal cavity $[26,27]$. Both brood care systems facilitate raising the young in densely packed communities.

Most cichlid species assemblages posed specific problems for comparative morphological methods: the accumulation of large numbers of closely related and morphologically similar taxa. It turned out that traditional morphometric methodology was pushed to its limitations and could not identify enough diagnostic characters to distinguish such closely related entities. Instead via de novo evolution of anatomical structures, cichlid diversification proceeded by modification of the same set of bones. New trophic niches were colonized by allometric changes together with shape modification of other body parts, so that cichlids could more efficiently adapt to novel food niches than other groups [28-30]. Despite clear ecological distinction many species are closely related and morphologically similar, and many diagnostic counts and measurements overlapped. This was the reason why geometric morphometrics was increasingly applied, often with dramatic success. It turned out that geometric morphometrics not only could address such subtle differences among individuals, populations, and species but also provided highly efficient means to assess multiple individuals in a quantitative way. Progress was also made in the selection and standardization of landmarks to avoid problems arising from potential influences from the subjectivity in placing particular landmarks. By stringent definition of particularly informative sets of landmarks, the body parts distinguishing the entities can be easily visualized and the underlying bony structures are identified.

By searching the current body of literature (Google Scholar, PubMed, British library, Scirus) we identified about 50 studies on cichlid fishes, applying the methods of geometric morphometrics (GM), hitherto. Seeded by D'Arcy Thompson's influential book on the mechanism of shape change published in 1917 [31], the discipline of geometric morphometrics started to become a widely used method in the early nineties $[32,33]$. The first study focusing on cichlid fishes was published in 2001 [34]. This paper will first give a summary of GM methods with references of the comprehensive descriptions. It builds on a series of previous reviews [33, 35-42], but focuses on the cichlid fish model system and includes previous work by categorizing them into topical questions relevant for cichlid evolutionary approaches. Later we outline the opportunities to tackle important evolutionary questions via GM methods.

\section{Overview on Geometric Morphometric Techniques}

The term "morphometrics" is generally used for the statistical analysis of a large amount of distances, angles, or ratios of angles. "Geometric morphometrics" deals directly with coordinates of anatomical landmarks, either in two or three dimensions, rather than with traditional distance or angle measurements. Landmark points have been defined by Bookstein [32] as loci that have names as well as Cartesian coordinates. The names are intended to imply true homology (biological correspondence) from form to form. In Figure 1 we provide illustrations of different landmarks applied in different studies on cichlids. In addition to homologous landmarks there is the possibility to define the socalled semilandmarks $[42,46]$ that incorporate information about curves and outlines of the investigated objects. A considerable amount of methodological development has been achieved in recent years, as summarized by Gunz et al. [47]. Many morphological traits can be quantified by just measuring size of particular body parts, but there are other traits which are more complex and cannot be quantified by size alone. For such traits one needs the information about their shape. Shape is mathematically defined as the geometrical information of an object that remains when location, scale, and rotational effects are filtered [48]. The most common method to filter those effects and to compute shape coordinates is the so-called Procrustes superimposition [48]. The name Procrustes comes from Greek mythology; Procrustes physically attacked his guests (victims) by stretching them or cutting off their legs so as to make them fit an iron bed's size. In contrast to the mythological derivation of the term Procrustes in GM the relative positions of landmarks within a configuration are kept and actually do not get "fitted to an iron bed" during the alignment. Figure 2 describes and illustrates the steps of 


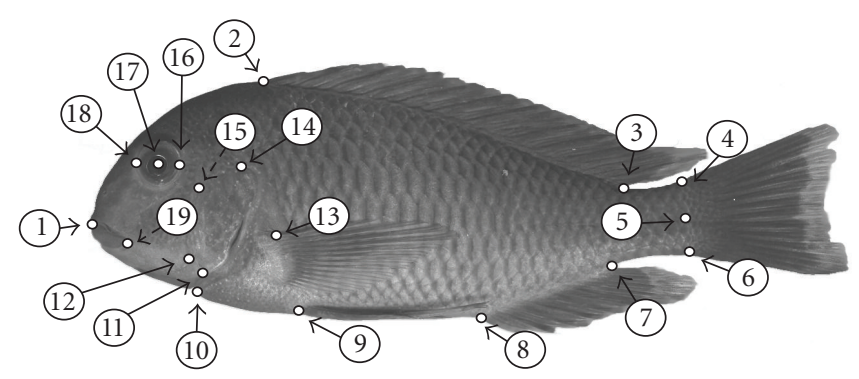

(a)

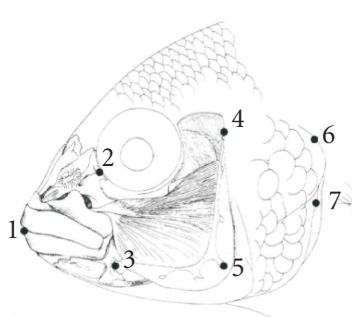

(b)

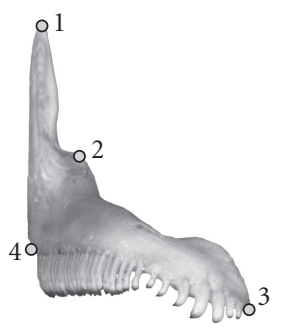

(c)

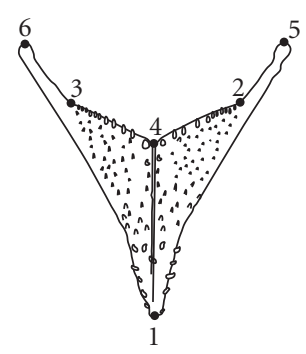

(d)

FIGURE 1: Landmarks on (a) cichlid overall body (b) cichlid head [43] (c) a bony element (premaxilla) [44] and (d) the lower pharyngeal jaw $[45]$.

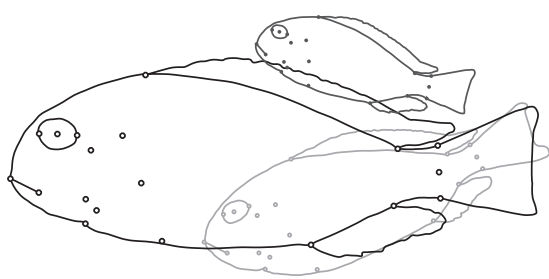

(a)

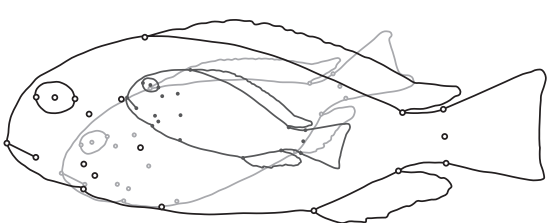

(b)

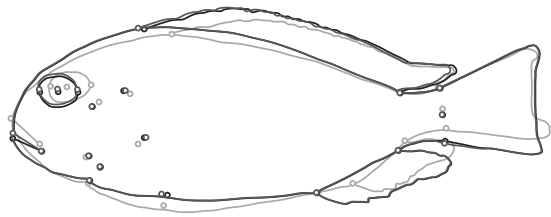

(d)

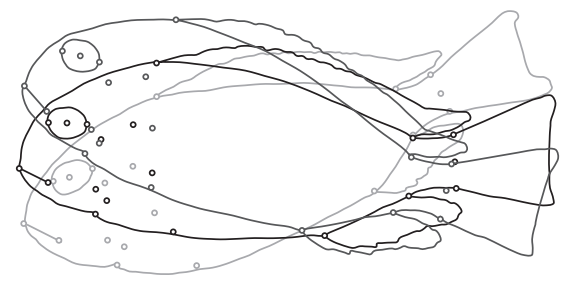

(c)

FIgURe 2: Illustration of the Procrustes superimposition of the (a) original configuration (raw coordinates). (b) First, the centroid of each configuration is translated to the origin. (c) After that, configurations are scaled to a common unit size and (d) optimally rotated to minimize the squared differences between corresponding landmarks.

Procrustes superimposition. We note that there are several other accepted methods to obtain shape coordinates but the Procrustes method is the most prevalent one. Once shape coordinates, which are a reduced number of variables that collectively describe the variation in the original shapes, have been derived, results can be visualized and any type of statistical analysis can be performed.

There is a large body of free software for geometric morphometric analysis available on the internet. A comprehensive list of such software, much of it provided free of charge by various authors, is maintained by F. James Rohlf on the SUNY at Stony Brook morphometrics homepage (http://life.bio.sunysb.edu/morph/).

\section{Application of GM to the Study of Cichlid Evolution}

\subsection{Addressing Cichlid Diversity-How and to Which Extent Do Groups of Cichlids Differ in Shape?}

Geometric morphometrics provide the opportunity to get new insights in the variety of morphological characteristics, discriminating genera, species, populations, and morphs or even individuals. Kassam et al. [49] compared groups of cichlids from different African lakes. They used landmarkbased geometric morphometric methods to test the hypothesis that Petrochromis species from Lake Tanganyika 
are ecomorphologically equivalent to Petrotilapia species from Lake Malawi. The study identified differences between the lakes, but demonstrated morphological equivalence for three species and hence their convergent evolution. In another interlake comparison published in 2007, Kassam et al. [50] emphasized the robustness of GM when testing the morphological equivalence hypothesis among cichlid species. A third study addressed the variation in body shape of the Central American Amphilophus citrinellus species complex from lakes of Nicaragua by means of GM [51]. In the same year, Parsons et al. [52] compared the results of several traditional morphometric analyses against geometric morphometric analyses. He applied traditional and geometric morphometric methods to a common data set, namely, two Nicaraguan species, and thereby showed that GM is the more effective method to analyze and interpret body form. This message was also given by Trapani [53], who compared dental morphs of cichlids and by Maderbacher et al. [54], where traditional and geometric morphometric methods were compared to discriminate populations of cichlids. Postl et al. [44] showed that GM is possible to discriminate even populations of the Tanganyikan cichlid Tropheus moorii, which was presumed not to differ in morphology but only in coloration. All mentioned studies have in common that they benefited from the fact that GM is not constrained by focusing on particular shape features a priori, so that it was possible to indentify differences in any direction of shape space. Such shape differences among groups can be easily visualized through deformation grids in the so-called thin-plate splines (see Figure 3 ).

\subsection{Trophic Ecology — What Do Differences/Similarities in Trophic Morphology Tell Us about Cichlids Evolution?}

Cichlid fishes exhibit a wide variety of feeding specializations, which appear to be strongly associated with adaptive changes in trophic morphology. So it stands to a reason that researchers quantify differences in trophic structures to obtain new insights into pathways of cichlid diversification. In 2001, Rüber and Adams [34] were the first to apply GM in a cichlid fish evolutionary study. By quantifying morphological variation in body shape and trophically associated traits among taxa of the endemic Lake Tanganyika tribe Eretmodini, they could argue that similar body shape and feeding strategies evolved multiple times in independent lineages, even within a single tribe of cichlids. Indirectly they demonstrated that body shape was not fully independent of trophic morphology. In another study on cichlid eco-morphology Bouton et al. [43] demonstrated that in haplochromine cichlids head shape varies between populations at rocky islands at distances of only kilometers apart and that this variation-possibly in response to environmental variables - may lead to allopatric divergence of rock-dwelling cichlids (the landmark set from this study is shown in Figure 1). In particular, morphology of oral and pharyngeal jaws was frequently investigated with GM methods. In one of those studies Albertson and Kocher [55] analyzed four skeletal elements of the oral jaws in two closely related species from Lake Malawi and their $\mathrm{F}_{1}$ hybrid

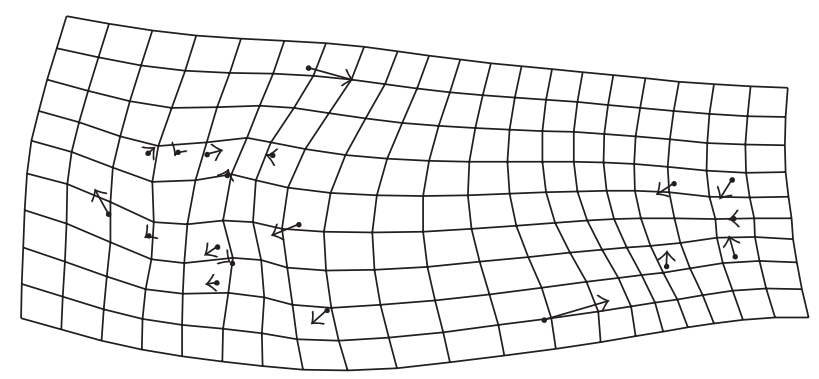

(a)

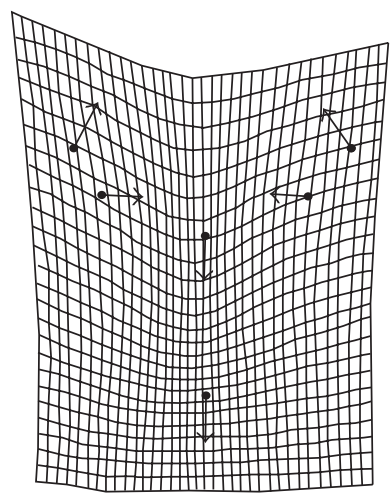

(b)

Figure 3: Deformation grid or Thin-plate spline showing differences (a) concerning whole body shape (19 landmarks, see Figure 1(a)) between a group of cichlid individuals living in the natural environment in Lake Tanganyika and another group of fish raised in ponds with a standardized rock architecture and artificial food. The grid accords to a canonical variate analysis carried out in an unpublished study on Lake Tanganyikan cichlids. (b) of the lower pharyngeal jaw throughout ontogeny between the smallest and the largest individual of Lepidiolamprologus elongatus ( 6 landmarks, see Figure 1(d)).

progeny. Because hybrids were significantly different from both parental species they suggested an additive mode of action for the alleles in question. This work formed the basis for three consecutive studies to further elucidate the genetic architecture of the cichlid jaw apparatus [56-58].

Kassam et al. [59] quantified the shape of several bony elements from head region and compared patterns of variation within and between zooplankton and algal feeders of cichlid fishes. They were able to distinguish among those groups, but also revealed trophic morphological variation between species within each trophic guild. Other studies showed that GM is not only applicable to quantify tooth shape in the oral jaw $[53,60]$ but is also an adequate method to investigate differences in pharyngeal jaws [45, $61,62]$. These studies confirmed that this structure is a highly adaptive morphological feature which is optimized for processing several different types of food in cichlid fishes.

It is worth mentioning that cichlid pharyngeal jaws were one of the first examples of object symmetry in geometric morphometrics [63]. They played an important role in developing new morphometrics methods studying symmetry and asymmetry. Those methods are available in specific "canned" software such as the specialized Sage 
program [64] and the more general MorphoJ package [65] and could be used in future studies concerning different topics in cichlid research for example, asymmetry in scaleeating cichlids [66].

\subsection{Growth Allometry —At What Time and for What Reason Do Morphological Differences Arise during Growth of a Cichlid?}

Since 1924 it has been established that morphological adaptation can proceed via allometry, the change in relative dimensions of body parts that are correlated with changes in overall size [31, 67]. Gould [68, 69] emphasized that changing size often means changing shape. In practice, such allometric relations can be studied during the growth of a single cichlid individual, between different individuals within one species or between different species. Fujimura and Okada [70] compared the shapes of the lower jaw bone during different stages of development of a Lake Victoria cichlid and a riverine cichlid using GM methods. Their data suggested that most shape change may have a similar pattern during the growth of both species. Differences in adult shape may be due to differences arising early in development, and not to the difference of shape change during growth. A very recent study [45] described allometric shape change of the lower pharyngeal jaw in a Lake Tanganyika cichlid fish and could correlate those shape changes to a dietary shift in ontogeny of this species. In Figure 3(b), which originated from the work of Hellig et al. [45], it becomes clear that illustration of results is one great advantage of GM.

Another topic often linked to that about allometry is sexual dimorphism. There are several studies dealing with sexual size dimorphism in cichlids [71-74] but only few authors have addressed shape dimorphism by applying GM methods. We found two studies where sexual dimorphism was touched on within another topic $[54,75]$ and one recent study by Herler et al. [76] where sexual dimorphism was investigated through geometric morphometrics and shape differences among sexes were assessed in relation to the differentiation of populations and species in a Lake Tanganyika cichlid genus.

3.4. Geometric Morphometrics as Valuable Tool in Integrative Evolutionary Studies on Cichlid Fishes. The following studies combined several approaches to address evolutionary questions. The first is meanwhile highly cited and presented a convincing case of sympatric speciation in the Midas cichlid species complex (Amphilophus spp.) in a crater lake in Nicaragua [61]. This study included phylogeographic, population-genetic (based on mitochondrial DNA, microsatellites, and amplified fragment length polymorphisms), ecological, and morphometric analyses, whereby morphometric analyses integrated quantification of body shape and shape of pharyngeal jaws by means of GM. Another integrative evolutionary study by Stewart and Albertson [77] focused on Lake Tanganyika scale-eating cichlids which show a frequency-balanced polymorphism in the left- and right-handedness of the mouth, as adaptation to scale-eating [78]. They addressed the evolution and development of craniofacial morphology and laterality in these cichlids. Indeed, their data supported a genetic basis for jaw laterality. They observed jaw laterality early in development and identified a conserved locus segregating with craniofacial handedness in East African cichlids.

Two other recent studies compared cichlids from the three East African lakes. The most recent from Cooper et al. [79] dissected specimens from 87 genera of cichlid fishes and compared head shapes and underlying structures using geometric morphometrics. The authors confirmed that specific changes in trophic morphology have evolved repeatedly in the African rift lakes. One year before another study on African cichlids and their adaptive radiation was published where GM methods played an important role. Young et al. [80] introduced a modified methodology of Principal Component Analysis (PCA) combined with a linear regression, called "ordered-axis plot." This novel approach is a powerful tool to detect patterns of divergence among separate groups in a common morphospace [80], although Parsons et al. [81] pointed out the limitations of this method in the application to general data sets.

Another comprehensive study on cichlid fishes, carried out by Stelkens et al. 2009 [82], produced interspecific $\mathrm{F}_{1}$ crosses of two African haplochromine cichlid fish species with a particularly large degree of pairwise genetic and phenotypic divergence. The transgression in multitrait shape phenotypes was quantified using GM methods. They concluded that hybridization may generate novel genotypes with adaptive potential and that interspecific hybridization has likely contributed to the rapid rate of phenotypic evolution in the adaptive radiations of haplochromine cichlids.

\section{Conclusions and Outlook}

To date about 50 publications have accumulated with a focus on cichlid fish adaptive evolution and adaptive radiation. Clearly, geometric morphometric methods are gaining importance in cichlid research, and several advantages became evident. These begin with the efficiency of data acquisition and end with the impressive potential for visualization of the results. Geometric morphometrics can be based on photographs and even computer scans of anesthetized fish, so that sacrificing and preserving of specimens is unnecessary, unless voucher specimens are needed or the investigated body parts require the dissection of an individual. The positioning of landmarks can be individually adapted to particular research questions, so that GM methods can be broadly applied for a wide variety of evolutionary questions involving complex shape changes. The sensitivity turned out to be high enough to address population-level questions involving (adaptive) shape changes. In contrast, traditional comparative morphological approaches are often based on selected measurements, and results are somewhat restricted to those few variables.

Other exciting topics with great potential would be the analysis of phenotypic plasticity and its influence on diversification, the genetics of adaptation and ecological speciation in conjunction with new-generation sequencing 
approaches or to study the modularity in the trophic apparatus. Allometric changes during growth might also bear great potential. Another issue is that all GM studies on cichlids were based upon 2-dimensional data. We are convinced that 3-dimensional data will rapidly become accessible in cichlid research, given the rapid progress in the field. To conclude, there are several promising trajectories to address important evolutionary questions via GM, so that there is no doubt that this field will evolve further rapidly.

\section{Acknowledgments}

The authors thank Stephan Koblmüller for his comments on their paper and discussion. Also, they are grateful to Tetsumi Takahashi and two anonymous reviewers for their insightful suggestions. This paper was funded by the Austrian Science Fund (Project P20994-B03) and the Commission of Interdisciplinary Ecological Studies of the Austrian Academy of Sciences (Project 2007-04).

\section{References}

[1] G. F. Turner, O. Seehausen, M. E. Knight, C. Allender, and R. L. Robinson, "How many species of cichlid fishes are there in African lakes?" Molecular Ecology, vol. 10, no. 3, pp. 793-806, 2001.

[2] S. Koblmüller, K. M. Sefc, and C. Sturmbauer, "The Lake Tanganyika cichlid species assemblage: recent advances in molecular phylogenetics," Hydrobiologia, vol. 615, no. 1, pp. 5-20, 2008.

[3] G. A. Boulenger, Catalogue of the Fresh-Water Fishes of Africa in the British Museum (Natural History), vol. 3, British Museum (Natural History), London, UK, 1898.

[4] G. Fryer and T. D. Iles, The Cichlid Fishes of the Great Lakes of Africa: Their Biology and Evolution, Oliver \& Boyd, Edinbourgh, UK, 1972.

[5] P. H. Greenwood, "Morphology, endemism and speciation in African cichlid fishes," Verhandlungen der Deutschen Zoologischen Gesellschaft, vol. 66, pp. 115-124, 1973.

[6] P. H. Greenwood, "The cichlid fishes of Lake Victoria, East Africa: the biology and evolution of a species flock," in Zoology, Bulletin of the British Museum (Natural History), supplement 6, Natural History Museum, London, UK, 1974.

[7] P. H. Greenwood, "What is a species flock?" in Evolution of Fish Species Flocks, A. A. Echelle and I. Kornfield, Eds., pp. 13-19, University of Maine at Orono Press, 1984.

[8] P. H. Greenwood, "African cichlids and evolutionary theories," in Evolution of Fish Species Flocks, A. A. Echelle and I. Kornfield, Eds., pp. 141-155, University of Maine at Orono Press, Orono, Me, USA, 1984.

[9] G. Barlow, The Cichlid Fishes: Nature's Grand Experiment In Evolution, Perseus Publishing, Cambridge, Mass, USA, 2000.

[10] P. Chakrabarty, "Testing conjectures about morphological diversity in cichlids of Lakes Malawi and Tanganyika," Copeia, vol. 2, pp. 359-373, 2005.

[11] R. Zardoya, D. M. Vollmer, C. Craddock, J. T. Streelman, S. A. Karl, and A. Meyer, "Evolutionary conservation of microsatellite flanking regions and their utility in resolving the phylogeny of cichlid fishes (Pisces: Perciformes)," Proceedings of the Royal Society London B, vol. 263, no. 1376, pp. 15891598, 1996.
[12] J. T. Streelman, R. Zardoya, A. Meyer, and S. A. Karl, "Multilocus phylogeny of cichlid fishes (Pisces: Perciformes): evolutionary comparison of microsatellite and single-copy nuclear loci," Molecular Biology and Evolution, vol. 15, no. 7, pp. 798-808, 1998.

[13] I. P. Farias, G. Orti, I. Sampaio, H. Schneider, and A. Meyer, "Mitochondrial DNA phylogeny of the family cichlidae: monophyly and fast molecular evolution of the neotropical assemblage," Journal of Molecular Evolution, vol. 48, no. 6, pp. 703-711, 1999.

[14] I. P. Farias, G. Ortí, and A. Meyer, "Total evidence: molecules, morphology, and the phylogenetics of cichlid fishes," Journal of Experimental Zoology, vol. 288, no. 1, pp. 76-92, 2000.

[15] J. S. Sparks, "Molecular phylogeny and biogeography of the Malagasy and South Asian cichlids (Teleostei: Perciformes: Cichlidae)," Molecular Phylogenetics and Evolution, vol. 30, no. 3, pp. 599-614, 2004.

[16] P. Chakrabarty, "Cichlid biogeography: comment and review," Fish and Fisheries, vol. 5, no. 2, pp. 97-119, 2004.

[17] C. Katongo, S. Koblmüller, N. Duftner, L. Makasa, and C. Sturmbauer, "Phylogeography and speciation in the Pseudocrenilabrus philander species complex in Zambian rivers," Hydrobiologia, vol. 542, no. 1, pp. 221-233, 2005.

[18] C. Katongo, S. Koblmüller, N. Duftner, L. Mumba, and C. Sturmbauer, "Evolutionary history and biogeographic affinities of the serranochromine cichlids in Zambian rivers," Molecular Phylogenetics and Evolution, vol. 45, no. 1, pp. 326338, 2007.

[19] S. Koblmüller, K. M. Sefc, N. Duftner, C. Katongo, T. Tomljanovic, and C. Sturmbauer, "A single mitochondrial haplotype and nuclear genetic differentiation in sympatric colour morphs of a riverine cichlid fish," Journal of Evolutionary Biology, vol. 21, no. 1, pp. 362-367, 2008.

[20] D. A. Joyce, D. H. Lunt, R. Bills et al., "An extant cichlid fish radiation emerged in an extinct Pleistocene lake," Nature, vol. 435, no. 7038, pp. 90-95, 2005.

[21] O. Seehausen, "African cichlid fish: a model system in adaptive radiation research," Proceedings of the Royal Society B, vol. 273, no. 1597, pp. 1987-1998, 2006.

[22] D. Schluter, The Ecology of Adaptive Radiation, Oxford University Press, Oxford, UK, 2000.

[23] C. Sturmbauer, "Explosive speciation in cichlid fishes of the African Great Lakes: a dynamic model of adaptive radiation," Journal of Fish Biology, vol. 53, supplement, pp. 18-36, 1998.

[24] J. B. Yoder, E. Clancey, S. Des Roches et al., "Ecological opportunity and the origin of adaptive radiations," Journal of Evolutionary Biology, vol. 23, no. 8, pp. 1581-1596, 2010.

[25] K. F. Liem, "Evolutionary strategies and morphological innovations: cichlid pharyngeal jaws," Systematic Biology, vol. 22, no. 4, pp. 425-441, 1973.

[26] N. B. Goodwin, S. Balshine-Earn, and J. D. Reynolds, "Evolutionary transitions in parental care in cichlid fish," Proceedings of the Royal Society B, vol. 265, no. 1412, pp. 2265-2272, 1998.

[27] M. L. J. Stiassny and A. Meyer, "Cichlids of the Rift lakes," Scientific American, vol. 280, pp. 64-69, 1999.

[28] M. L. J. Stiassny, "Phylogenetic interrelationships of the family Cichlidae: an overview," in Cichlid Fishes, Behaviour, Ecology and Evolution, M. H. A. Keenleyside, Ed., pp. 1-35, Chapman \& Hall, London, UK, 1991.

[29] R. C. Albertson, J. A. Markert, P. D. Danley, and T. D. Kocher, "Phytogeny of a rapidly evolving clade: the cichlid fishes of Lake Malawi, East Africa," Proceedings of the National Academy of Sciences of the United States of America, vol. 96, no. 9, pp. 5107-5110, 1999. 
[30] C. Clabaut, P. M. Bunje, W. Salzburger, and A. Meyer, "Geometric morphometric analyses provide evidence for the adaptive character of the Tanganyikan cichlid fish radiations," Evolution, vol. 61, no. 3, pp. 560-578, 2007.

[31] D. A. W. Thompson, On Growth and Form, Cambridge University Press, Cambridge, UK, 1917.

[32] F. L. Bookstein, Morphometric Tools for Landmark Data: Geometry and Biology, Cambridge University Press, New York, NY, USA, 1991.

[33] F. J. Rohlf and L. F. Marcus, "A revolution in morphometrics," Trends in Ecology and Evolution, vol. 8, no. 4, pp. 129-132, 1993.

[34] L. Rüber and D. C. Adams, "Evolutionary convergence of body shape and trophic morphology in cichlids from Lake Tanganyika," Journal of Evolutionary Biology, vol. 14, no. 2, pp. 325-332, 2001.

[35] F. J. Rohlf, "Morphometrics," Annual Review of Ecology and Systematics, vol. 21, no. 1, pp. 299-316, 1990.

[36] F. L. Bookstein, "Biometrics, biomathematics and the morphometric synthesis," Bulletin of Mathematical Biology, vol. 58, no. 2, pp. 313-365, 1996.

[37] D. C. Adams, F. J. Rohlf, and D. E. Slice, "Geometric morphometrics: ten years of progress following the "revolution"," The Italian Journal of Zoology, vol. 71, no. 1, pp. 5-16, 2004.

[38] M. L. Zelditch, D. L. Swidersky, H. D. Sheeds, and W. L. Fink, Geometric Morphometrics for Biologists: A Primer, Elsevier Academic Press, New York, NY, USA, 2004.

[39] D. E. Slice, "Geometric morphometrics," Annual Review of Anthropology, vol. 36, no. 1, pp. 261-281, 2007.

[40] P. Mitteroecker and P. Gunz, "Advances in geometric morphometrics," Evolutionary Biology, vol. 36, no. 2, pp. 235-247, 2009.

[41] C. P. Klingenberg, "Evolution and development of shape: integrating quantitative approaches," Nature Reviews Genetics, vol. 11 , no. 9, pp. 623-635, 2010.

[42] A. M. Lawing and P. D. Polly, "Geometric morphometrics: recent applications to the study of evolution and development," Journal of Zoology, vol. 280, no. 1, pp. 1-7, 2010.

[43] N. Bouton, F. Witte, and J. J. M. Van Alphen, "Experimental evidence for adaptive phenotypic plasticity in a rock-dwelling cichlid fish from Lake Victoria," Biological Journal of the Linnean Society, vol. 77, no. 2, pp. 185-192, 2002.

[44] L. Postl, J. Herler, C. Bauer, M. Maderbacher, L. Makasa, and C. Sturmbauer, "Geometric morphometrics applied to viscerocranial bones in three populations of the Lake Tanganyika cichlid fish Tropheus moorii," Journal of Zoological Systematics and Evolutionary Research, vol. 46, no. 3, pp. 240-248, 2008.

[45] C. J. Hellig, M. Kerschbaumer, K. M. Sefc, and S. Koblmüller, "Allometric shape change of the lower pharyngeal jaw correlates with a dietary shift to piscivory in a cichlid fish," Naturwissenschaften, vol. 97, no. 7, pp. 663-672, 2010.

[46] F. L. Bookstein, "Applying landmark methods to biological outline data," in Proceedings in Image Fusion and Shape Variability, K. V. Mardia, C. A. Gill, and I. L. Dryden, Eds., pp. 79-87, University of Leeds Press, Leeds, UK, 1996.

[47] P. Gunz, P. Mitteroecker, and F. L. Bookstein, "Semilandmarks in three dimensions," in Modern Morphometrics in Physical Anthropology, D. E. Slice, Ed., pp. 73-98, Kluwer Academic/Plenum Publishers, New York, NY, USA, 2005.

[48] I. L. Dryden and K. V. Mardia, Statistical Shape Analysis, John Wiley \& Sons, New York, NY, USA, 1998.
[49] D. D. Kassam, D. C. Adams, M. Hori, and K. Yamaoka, "Morphometric analysis on ecomorphologically equivalent cichlid species from Lakes Malawi and Tanganyika," Journal of Zoology, vol. 260, no. 2, pp. 153-157, 2003.

[50] D. Kassam, K. Yamaoka, B. Rusuwa, and M. Hori, "The robustness of geometric morphometrics in testing the morphological equivalence hypothesis among cichlid species from East African Great Lakes," Biological Journal of the Linnean Society, vol. 91, no. 1, pp. 1-9, 2007.

[51] C. P. Klingenberg, M. Barluenga, and A. Meyer, "Body shape variation in cichlid fishes of the Amphilophus citrinellus species complex," Biological Journal of the Linnean Society, vol. 80, no. 3, pp. 397-408, 2003.

[52] K. J. Parsons, B. W. Robinson, and T. Hrbek, "Getting into shape," Environmental Biology of Fishes, vol. 67, no. 4, pp. 417431, 2003.

[53] J. Trapani, "A morphometric analysis of polymorphism in the pharyngeal dentition of Cichlasoma minckleyi (Teleostei: Cichlidae)," Archives of Oral Biology, vol. 49, no. 10, pp. 825835, 2004.

[54] M. Maderbacher, C. Bauer, J. Herler, L. Postl, L. Makasa, and C. Sturmbauer, "Assessment of traditional versus geometric morphometrics for discriminating populations of the Tropheus moorii species complex (Teleostei: Cichlidae), a Lake Tanganyika model for allopatric speciation," Journal of Zoological Systematics and Evolutionary Research, vol. 46, no. 2, pp. 153-161, 2008.

[55] R. C. Albertson and T. D. Kocher, "Assessing morphological differences in an adaptive trait: a landmark-based morphometric approach," Journal of Experimental Zoology, vol. 289, no. 6, pp. 385-403, 2001.

[56] R. C. Albertson, J. T. Streelman, and T. D. Kocher, "Directional selection has shaped the oral jaws of Lake Malawi cichlid fishes," Proceedings of the National Academy of Sciences of the United States of America, vol. 100, no. 9, pp. 5252-5257, 2003.

[57] R. C. Albertson, J. T. Streelman, and T. D. Kocher, "Genetic basis of adaptive shape differences in the cichlid head," Journal of Heredity, vol. 94, no. 4, pp. 291-301, 2003.

[58] R. C. Albertson, J. T. Streelman, T. D. Kocher, and P. C. Yelick, "Integration and evolution of the cichlid mandible: the molecular basis of alternate feeding strategies," Proceedings of the National Academy of Sciences of the United States of America, vol. 102, no. 45, pp. 16287-16292, 2005.

[59] D. D. Kassam, D. C. Adams, and K. Yamaoka, "Functional significance of variation in trophic morphology within feeding microhabitat-differentiated cichlid species in Lake Malawi," Animal Biology, vol. 54, no. 1, pp. 77-90, 2004.

[60] J. T. Streelman, R. C. Albertson, and T. D. Kocher, "Variation in body size and trophic morphology within and among genetically differentiated populations of the cichlid fish, Metriaclima zebra, from Lake Malawi," Freshwater Biology, vol. 52, no. 3, pp. 525-538, 2007.

[61] M. Barluenga, K. N. Stölting, W. Salzburger, M. Muschick, and A. Meyer, "Sympatric speciation in Nicaraguan crater lake cichlid fish," Nature, vol. 439, no. 7077, pp. 719-723, 2006.

[62] C. D. Hulsey, R. J. Roberts, A. S. P. Lin, R. Guldberg, and J. T. Streelman, "Convergence in a mechanically complex phenotype: detecting structural adaptations for crushing in cichlid fish," Evolution, vol. 62, no. 7, pp. 1587-1599, 2008.

[63] C. P. Klingenberg, M. Barluenga, and A. Meyer, "Shape analysis of symmetric structures: quantifying variation among individuals and asymmetry," Evolution, vol. 56, no. 10, pp. 1909-1920, 2002. 
[64] E. Marquez, "Sage: symmetry and asymmetry in geometric data," http://www-personal.umich.edu/ emarquez/morph/.

[65] C. P. Klingenberg, "MorphoJ: an integrated software package for geometric morphometrics," http://www.flywings.org.uk/ MorphoJ_page.htm.

[66] T. J. M. Van Dooren, H. A. Van Goor, and M. Van Putten, "Handedness and asymmetry in scale-eating cichlids: antisymmetries of different strength," Evolution, vol. 64, no. 7, pp. 2159-2165, 2010.

[67] J. S. Huxley, "Constant differential growth-ratios and their significance," Nature, vol. 114, no. 2877, pp. 895-896, 1924.

[68] S. J. Gould, "Allometry and size in ontogeny and phylogeny," Biological Reviews, vol. 41, no. 4, pp. 587-640, 1966.

[69] S. J. Gould, Ontogeny and Phylogeny, Harvard University Press, Cambridge, Mass, USA, 1977.

[70] K. Fujimura and N. Okada, "Shaping of the lower jaw bone during growth of Nile tilapia Oreochromis niloticus and a Lake Victoria cichlid Haplochromis chilotes: a geometric morphometric approach," Development Growth \& Differentiation, vol. 50, no. 8, pp. 653-663, 2008.

[71] R. F. Oliveira and V. C. Almada, "Sexual dimorphism and allometry of external morphology in Oreochromis mossambicus," Journal of Fish Biology, vol. 46, no. 6, pp. 1055-1064, 1995.

[72] A. Erlandsson and A. J. Ribbink, "Patterns of sexual size dimorphism in African cichlid fishes," South African Journal of Science, vol. 93, no. 11-12, pp. 498-508, 1997.

[73] D. Schütz and M. Taborsky, "Giant males or dwarf females: what determines the extreme sexual size dimorphism in Lamprologus callipterus?" Journal of Fish Biology, vol. 57, no. 5, pp. 1254-1265, 2000.

[74] K. Ota, M. Kohda, and T. Sato, "Unusual allometry for sexual size dimorphism in a cichlid where males are extremely larger than females," Journal of Biosciences, vol. 35, no. 2, pp. 257265, 2010 .

[75] D. Kassam, S. Mizoiri, and K. Yamaoka, "Interspecific variation of body shape and sexual dimorphism in three coexisting species of the genus petrotilapia (Teleostei: Cichlidae) from Lake Malawi," Ichthyological Research, vol. 51, no. 3, pp. 195201, 2004.

[76] J. Herler, M. Kerschbaumer, P. Mitteroecker, L. Postl, and C. Sturmbauer, "Sexual dimorphism and population divergence in the Lake Tanganyika cichlid fish genus Tropheus," Frontiers in Zoology, vol. 7, article 4, 2010.

[77] T. A. Stewart and R. C. Albertson, "Evolution of a unique predatory feeding apparatus: functional anatomy, development and a genetic locus for jaw laterality in Lake Tanganyika scale-eating cichlids," BMC Biology, vol. 8, article 8, 2010.

[78] R. Takahashi, K. Watanabe, M. Nishida, and M. Hori, "Evolution of feeding specialization in Tanganyikan scale-eating cichlids: a molecular phylogenetic approach," BMC Evolutionary Biology, vol. 7, no. 1, article 195, 2007.

[79] W. J. Cooper, K. Parsons, A. McIntyre, B. Kern, A. McGeeMoore, and R. C. Albertson, "Bentho-pelagic divergence of cichlid feeding architecture was prodigious and consistent during multiple adaptive radiations within African RiftLakes," PLoS ONE, vol. 5, article e9551, no. 3, 2010.

[80] K. A. Young, J. Snoeks, and O. Seehausen, "Morphological diversity and the roles of contingency, chance and deter-minism in African cichlid radiations," PLoS ONE, vol. 4, article e4740, no. 3, 2009.
[81] K. J. Parsons, W. J. Cooper, and R. C. Albertson, "Limits of principal components analysis for producing a common trait space: Implications for inferring selection, contingency, and chance in evolution," PLoS ONE, vol. 4, article e7957, no. 11, 2009.

[82] R. B. Stelkens, C. Schmid, O. Selz, and O. Seehausen, "Phenotypic novelty in experimental hybrids is predicted by the genetic distance between species of cichlid fish," BMC Evolutionary Biology, vol. 9, article 283, 2009. 

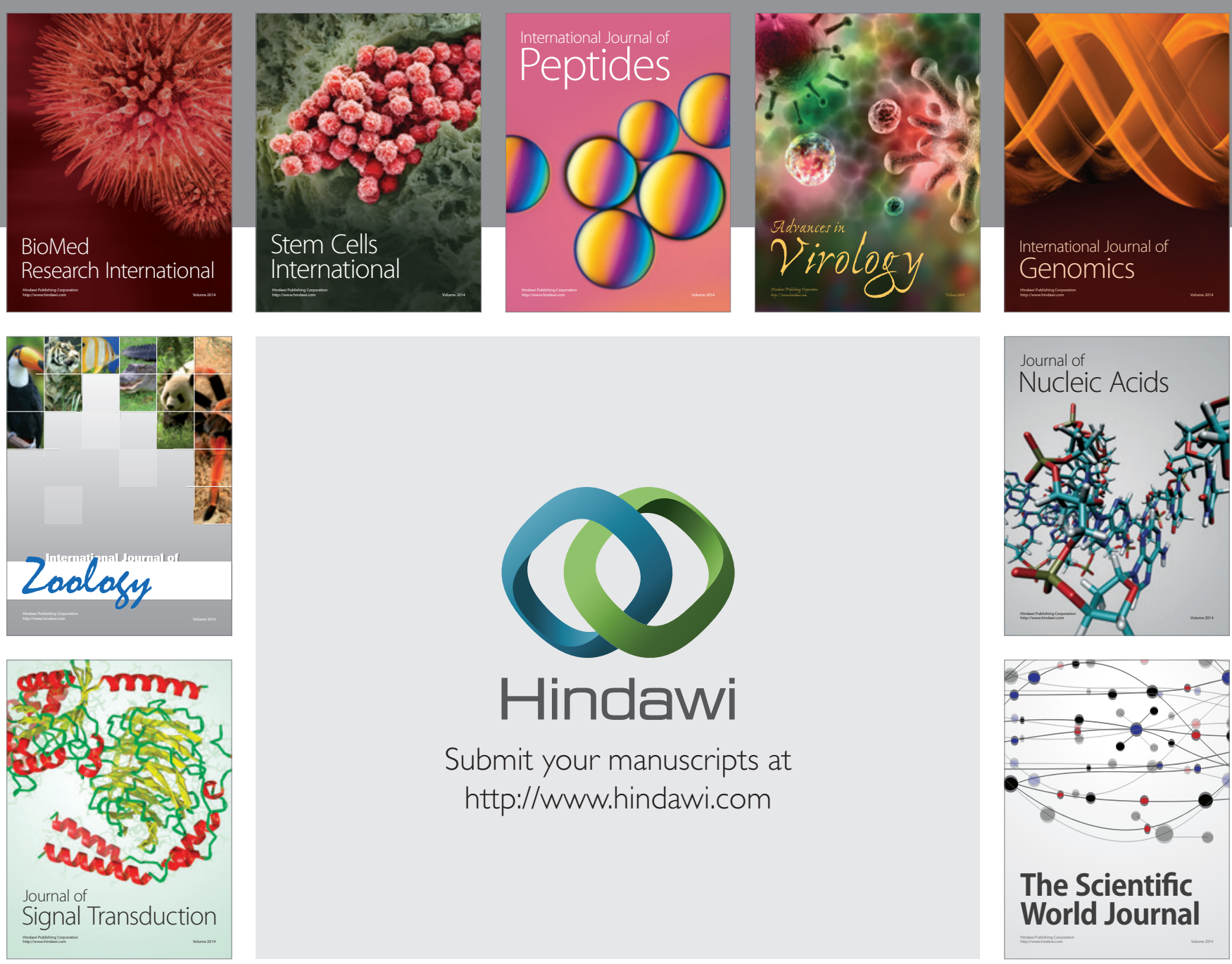

Submit your manuscripts at

http://www.hindawi.com
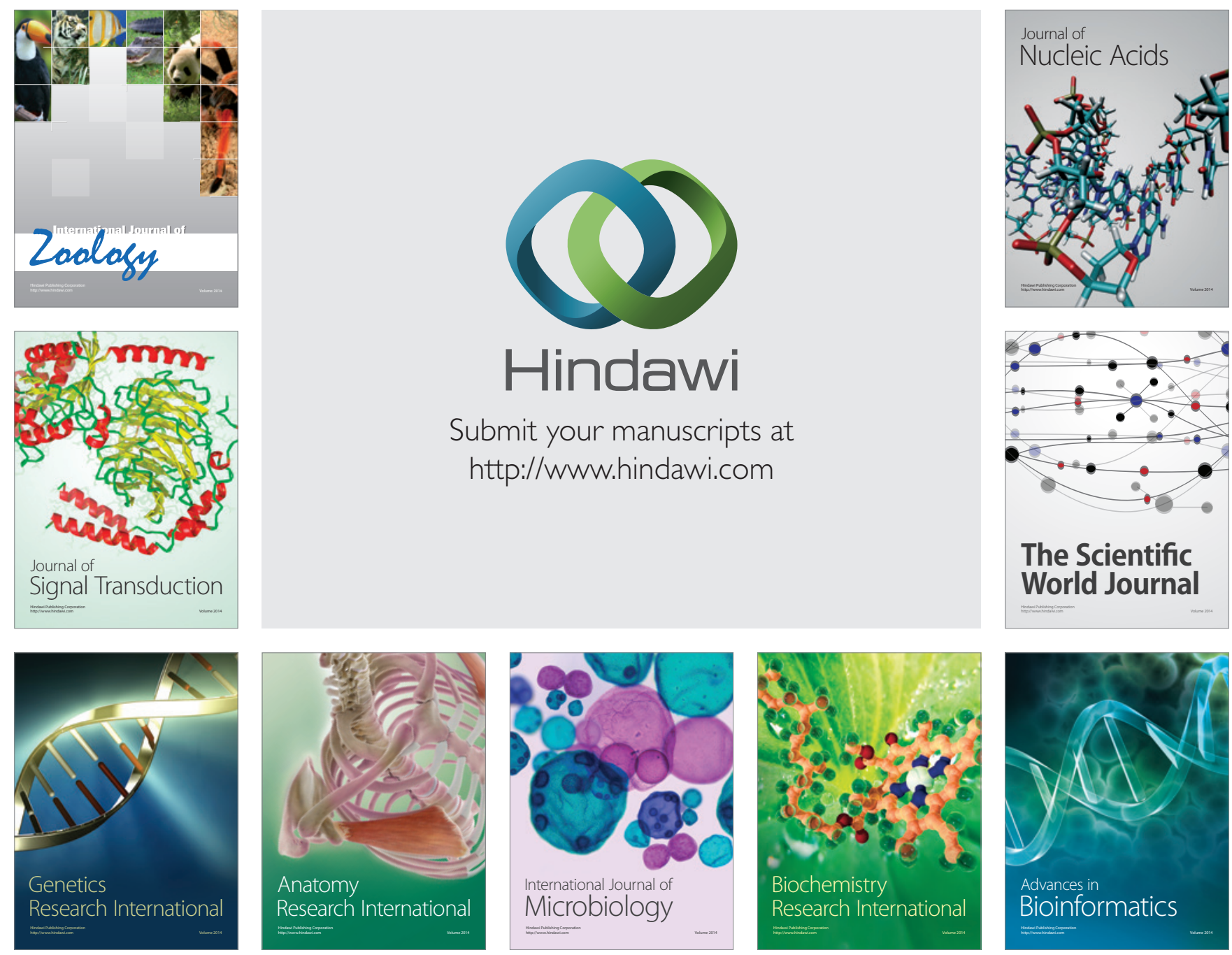

The Scientific World Journal
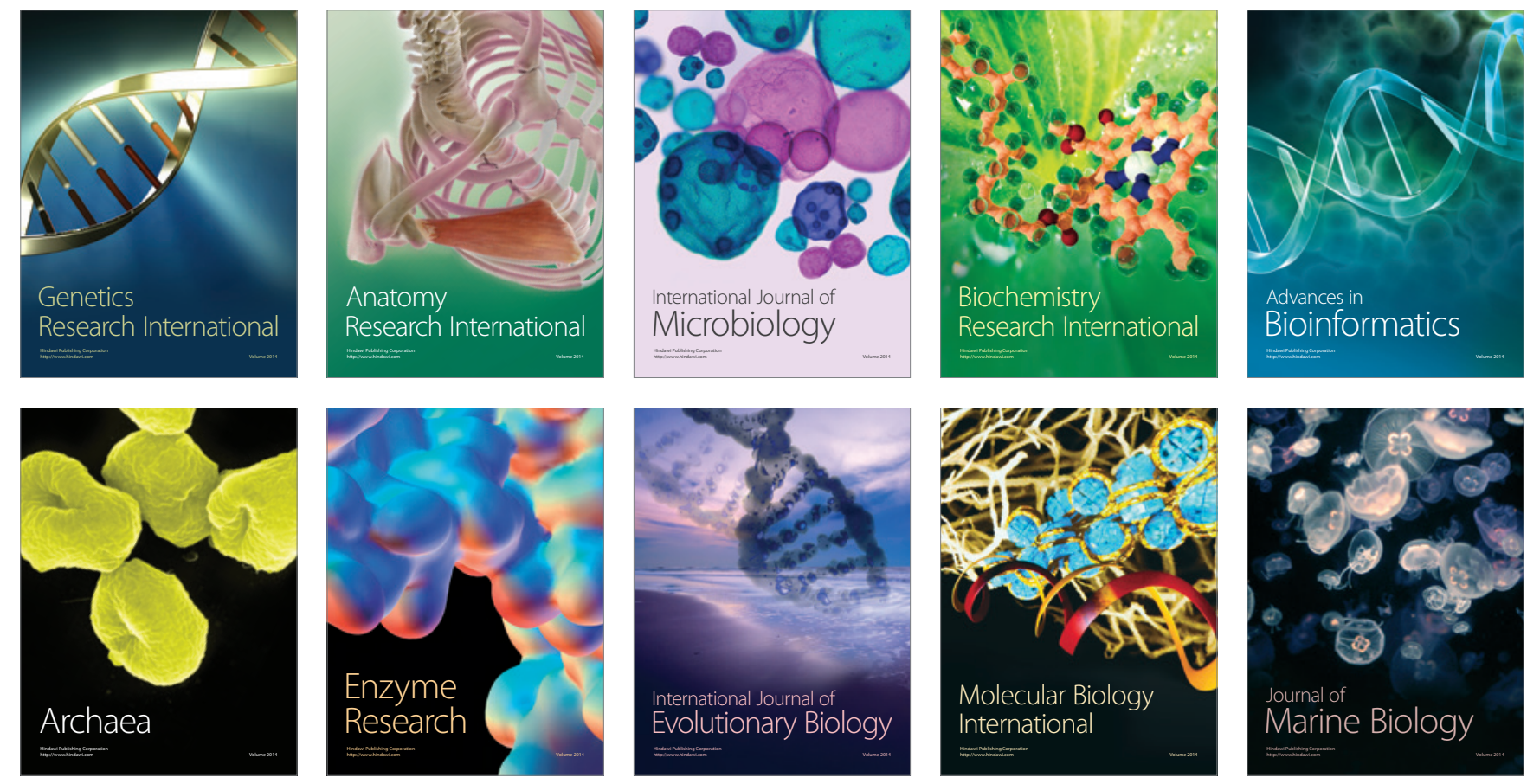